Eduardo C. Yap, $M D^{1,2}$

'Belo Medical Group

2Department of ENT

Metropolitan Medical Center
Correspondence: Dr. Eduardo C. Yap

Unit 3, 28 Times St., West Triangle, Quezon City 1104 Philippines

Phone: (632) 2547881

Email: edcyap88@gmail.com

Reprints will not be available from the author.

The author declared that this represents original material that is not being considered for publication elsewhere in full or in part, in print or electronic media; that the manuscript has been read and approved by the author, that the requirements for authorship have been met by the author, and that the author believes that the manuscript represents honest work.

Disclosures: The author signed a disclosure that there are no financial or other (including personal) relationships, intellectual passion, political or religious beliefs, and institutional affiliations that might lead to a conflict of interest

\section{Principles of Structural Rhinoplasty in South East Asian Noses}

What makes the majority of noses beautiful? It is the tip.,1,2,3

South East Asian noses are usually small and short with bulbous tip and thick skin and soft tissue envelope (SSTE). ${ }^{2}$ The tip is determined by the shape and strength of the lower cartilages. ${ }^{2,3,4}$ The lower cartilages are usually soft and weak so there is a need for a strong support system for the attachment of the lower cartilages. Thus, the surgical term is called "Structural Rhinoplasty."2,3

The concept of the surgery involves re-structuring the tip to a new position for elongation and projection. Since the septum is the most stable structure, a central part of the septum is harvested and is used as extended septal support graft for fixation of the lower cartilage for a whole new tip position. ${ }^{2,3}$ The open approach is often used. The SSTE dissection is wide up to the pyriform aperture laterally, nasal spine inferiorly and glabella superiorly. Make certain that the dissection plane is below the superficial muscular aponeurotic system (SMAS) in the upper cartilage (UC) and lower cartilage (LC) and below the periosteum in the nasal bone.

\section{SEPTOPLASTY}

\section{"Two points determine a line: a guide to anterior approach of the septum"}

Once the transcolumellar incision is done and all external nasal anatomy is exposed, the septum can be easily approached via the concept " 2 points determine a line." One point is at the area of the footplate which is separated from each other via blunt dissection down to the nasal spine. The other point is the anterior septal angle which is easily palpated. An imaginary line between the two points is the membranous septum which can be safely cut and opened via sharp dissection till one reaches the caudal margin of the septum. (Figure 1)

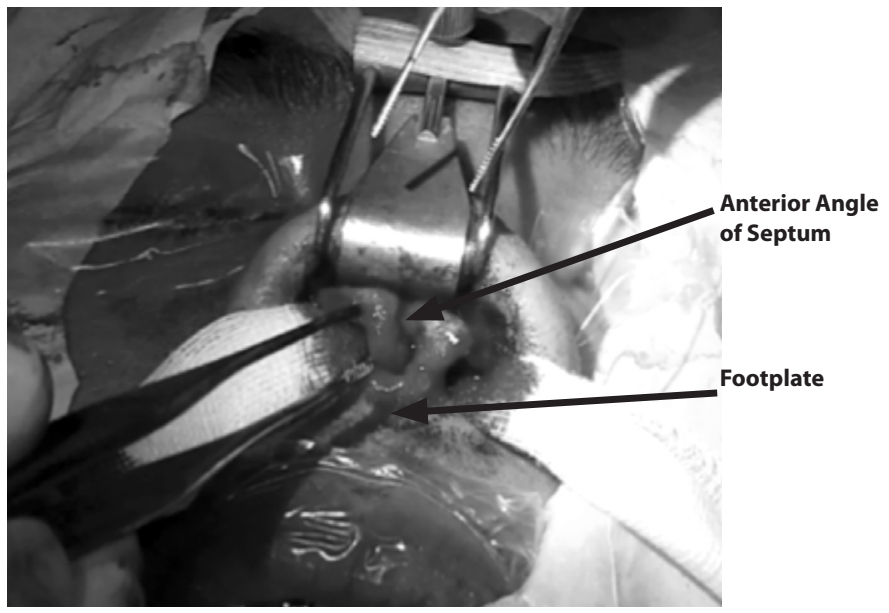

Figure 1. Two points determine a line: Anterior approach to the septum by identifying the 2 points landmarks: footplate and anterior angle of septum

After the caudal edge of the septum is identified, dissection of septum can be facilitated using converse or tenotomy scissors for sharp dissection on either side for 2-3mm until a submucoperichondrial plane is reached. Once the plane is identified, further dissection is done using a sharp Freer elevator. Dissection may reach up to vomer and the entire bony septum. 
The dissection can be unilateral or bilateral depending on the septal deviation.

After the mucoperichondrium is freed unilaterally, the central part of the septum can be harvested by initially scoring dorsally and caudally, leaving enough cartilage for support of the tip and dorsum. Using a Cottle elevator, the scored cartilage is entered making sure that the contralateral mucoperichondrium is not perforated. The contralateral side is then dissected in the submucoperichondrial plane. The cartilage is further mobilized using a side sharp periosteal elevator to dislocate the cartilage from the perpendicular plate of the ethmoid and the vomer. The most adherent part is at the palatine crest. The central cartilage can be removed and any bony spurs and deviation can be trimmed using a rongeur. Generally a $10 \mathrm{~mm}$ dorsal and caudal strut should be left behind for support.

If the mucoperichondrium is dissected bilaterally, harvesting the central cartilage will be easier. (Figure 2)

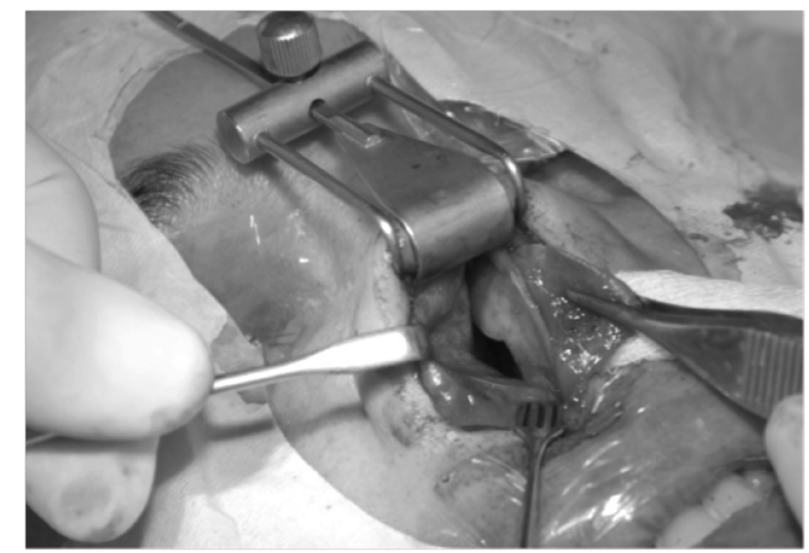

Figure 2. Dorsal and Caudal Struts

At this stage, any septal deviation and the internal valve can be corrected by several methods. Deviated dorsal struts can be corrected with a spreader graft. A deviated caudal strut can be corrected by scoring the concave side and fixing a support graft e.g. Septal Extension Graft (SEG)., ${ }^{3,4}$ A tight internal valve can be widened by a spreader graft. (Figure 5) Quilt closure of the septal mucosa using vicryl 5-0 can be done at this stage or at a later stage of surgery when the tip is repositioned to the desired projection.

STRUCTURAL SEPTORHINOPLASTY: Achieving functionality with good form

\section{Analysis of the Tip}

Southeast Asian noses are usually bulbous which may be due to thick fatty skin and/or convex lower lateral cartilages (LLC). A bulbous tip can be corrected by cephalic trim for convex LLC. Using fine hooks or Brown Adson forceps, the LLC is retracted caudally and the cephalic border identified. A slim strip of LLC cartilage is incised using a blade 15 leaving at least $5-8 \mathrm{~mm}$ of caudal LLC intact. The cephalic cartilage is then carefully raised from the mucosa. Avoid excessive cephalic trim because it may lead to depressed LLC consequently causing external valve collapse and rotation of the tip. ${ }^{2}$

\section{Tip Suture Technique:}

For LLC that do not have a defined dome, a domal suture can be done to achieve a sharper tip. Suturing is a simple mattress PDS 5-0 suture at the tip to bring closer the lateral and medial component of the dome. If further narrowing of the tip is required, both domes can be sutured at the cephalic side. Tip suturing does not project the tip; it just narrows the width of the tip.' Subcutaneous fat can be trimmed if the final appearance of the tip is still bulbous. (Figure 3)

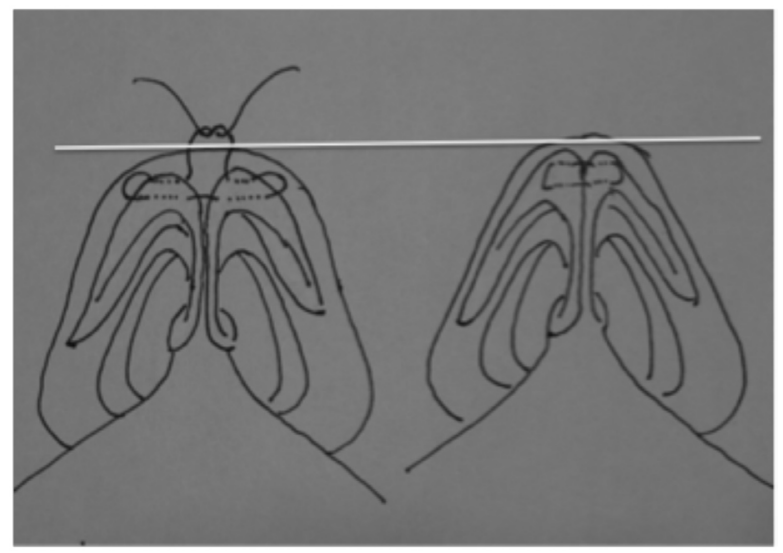

Figure 3. Domal and interdomal suturing narrows the tip. It does not project the tip

\section{Tip Directions: Projection vs. De-projection and Rotation vs. Counter-rotation:}

Most Asian nasal tips need projection and elongation (counter rotation). ${ }^{3}$ If minimal correction is needed then a columellar strut and a tip shield graft can be used. If major tip repositioning is required, then a Septal Extension Graft (SEG) or extended spreader graft is needed. The central harvested cartilage is sutured at the caudal strut of the septum using PDS 5-0. Fixation of the SEG needs 3-4 sutures. (Figure 4) Once the SEG is fixed to the desired position, the dome and medial crura can be sutured to the caudal end of the SEG using PDS 5-0.

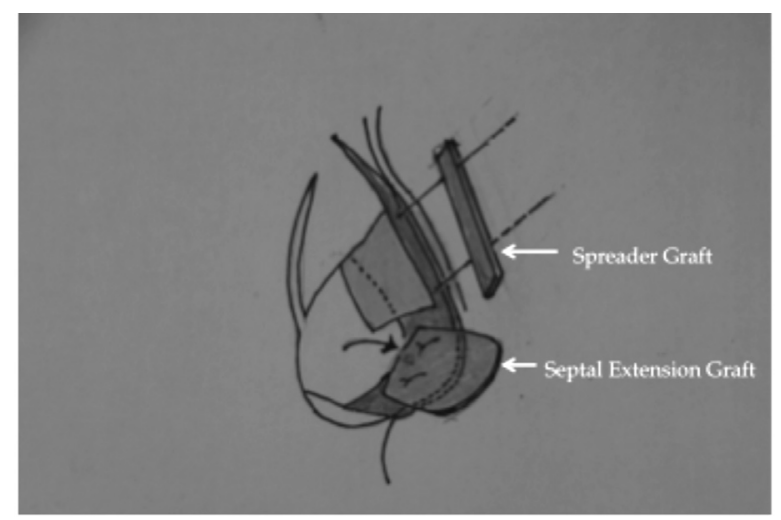

Figure 4. Two most common Support Grafts: Spreader and Septal Extension Graft

Once the $L C$ is fixed to the SEG, contoured tip grafts either from concha or septum can be used to further define the tip.

Once the tip is already at the desired position, a dorsal graft can be fashioned to blend the new tip with the radix. Dorsal grafts may 
be cartilage, silicon or expanded polytetrafluoroethylene (e-PTFE, popularly known as Gore-Tex'). (Figure 5)

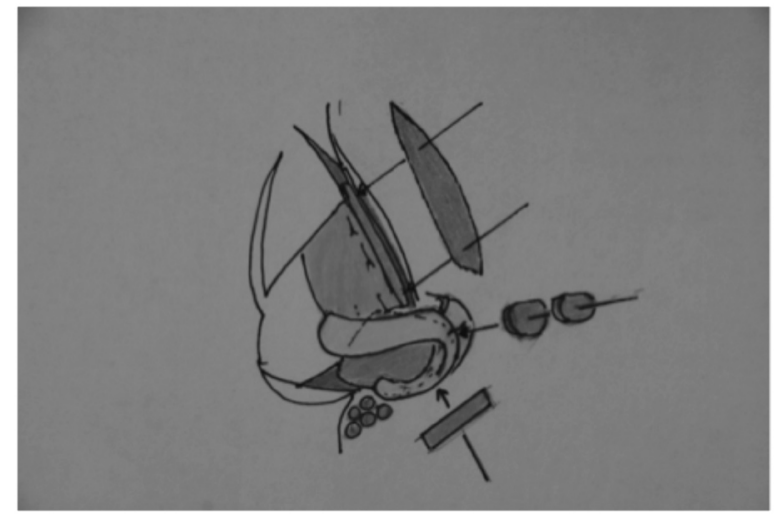

Figure 5. Common grafts in Structural SeptoRhinoplasty: Dorsal, Spreader, SEG, Onlay tip, Columellar Strut

Expanded polytetrafluoroethylene (e-PTFE) or Gore-Tex ${ }^{\circ}$ has gained popularity because of its better aesthetic outcome. It was initially introduced in the market as sheets however recently many companies produced preformed e-PTFE of various shapes and sizes. This implant is now preferred because it is more natural looking and heals with tissue adhesion. ${ }^{5}$ Despite it being less visible as an implant, there are times that it may show under thin skin. In order to make the e-PTFE implant better looking, the sides of the implant should be cut and carved well to avoid cornering appearance. Make certain implant placement is midline and in full contact with undersurface. Since e-PTFE is soft, it is not used in tip support surgery. One dreadful complication of e-PTFE is infection. Infection can be avoided by diligently observing sterility, e.g. soaking the implant in gentamycin solution when not in use and avoidance of prolonged air exposure. The implant package should be opened only when it is time for insertion. The caudal edges of the implant should be clear of and away from the incision line since the incision wound can be the site of entry of microorganisms.

Trial closure is made and the tip is palpated. Additional tip grafts may be used for refinement. (Figure 6) The membranous and cartilaginous septal mucosa is then sutured using Vicryl 5-0 running quilt closure.

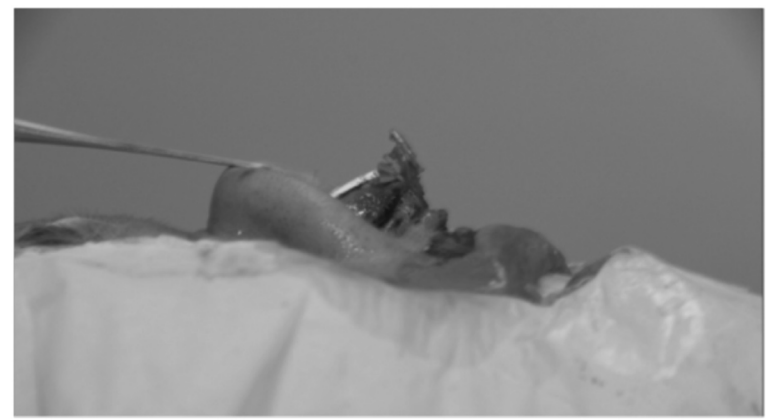

Figure 6. Final tip defining grafts and an e-PTFE dorsal implant.

Closure of the transcolumellar incision starts first with subcutaneous fixation using vicryl 6-0 and skin closure using nylon 6-0. The marginal incision is closed using Vicryl 6-0 simple interrupted

\section{ADJUNCTIVE PROCEDURES FOR THE ALA}

Majority of Southeast Asian Noses have a certain degree of hanging ala. The alar rim can be lifted by excision of a triangular piece of tissue in the inner lateral vestibular skin. The irregular triangular piece of skin tissue is shaped like a sail of a sailboat. ${ }^{6,7}$ The two sides are marked as the inner alar rim margin and a skin groove in the lateral vestibule area marked by transition of thin vibrissae to thick vibrissae. The defect is closed using nylon 6-0 simple interrupted. The alar rim skin is made to roll cephalically as a flap thus lifting the whole alar rim. (Figure 7) The sail excision is usually done as the first procedure in rhinoplasty in order to allow maximum flexibility of maneuvering the ala from marking, incision, excision and suturing.

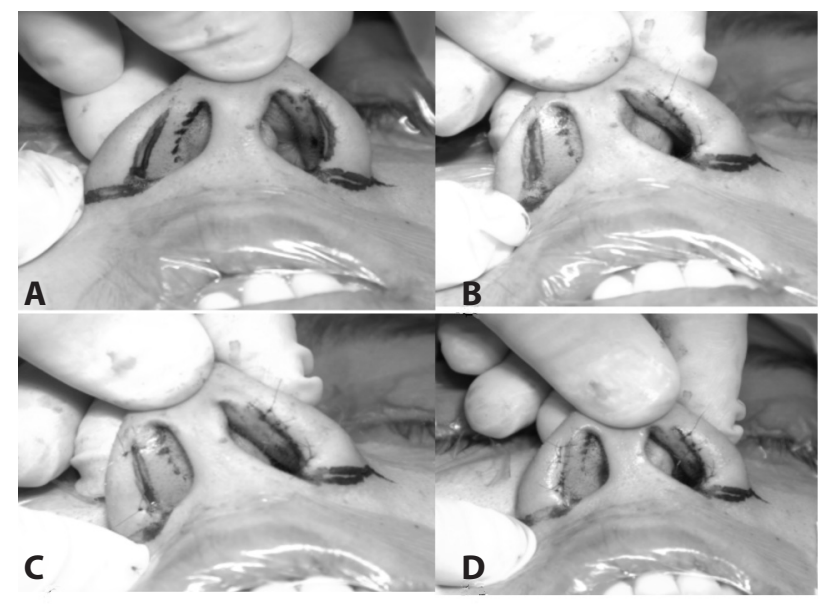

Figure 7. Summary of Sail Excision for correction of hanging ala. A. Marking of Sail. B. Excision of skin and subcutaneous tissue, right alar. Note the finished trimming in the left ala. C. Nylon 6-0 is used for closure of the defect. It starts initially at both ends to avoid dog-ear deformity. D. Immediate postop

A common feature also in Southeast Asian noses is the wide alar base and flared ala. ${ }^{3}$ The correction is a 3-dimensional approach wherein the sill can be excised via a wedge incision to narrow the base and if the wedge is extended laterally, the flaring can be corrected. (Figure 8)

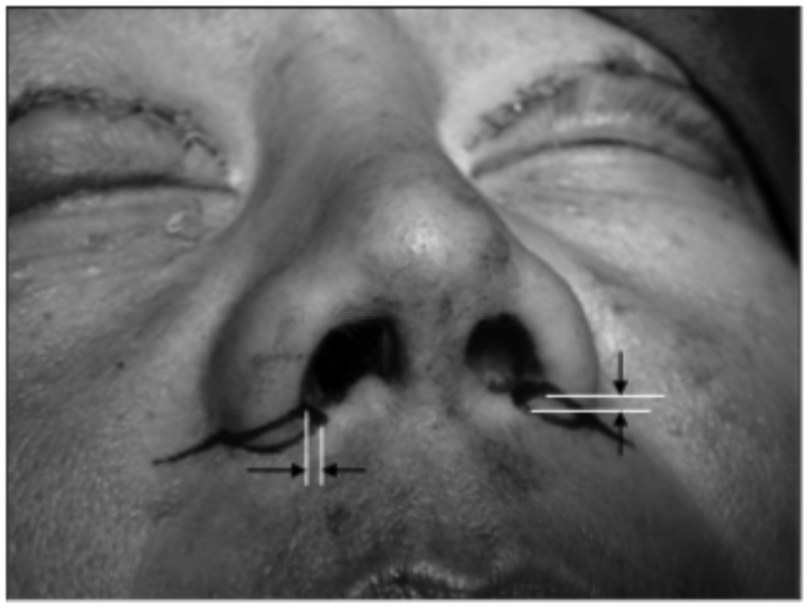

Figure 8. Correction of wide alar base and alar flare 
The newly re-structured nose should look better before final closure. Palpation is important to detect minor defects. Everyone in the operating room including the surgeon should be satisfied with the outcome. (Figure 9)
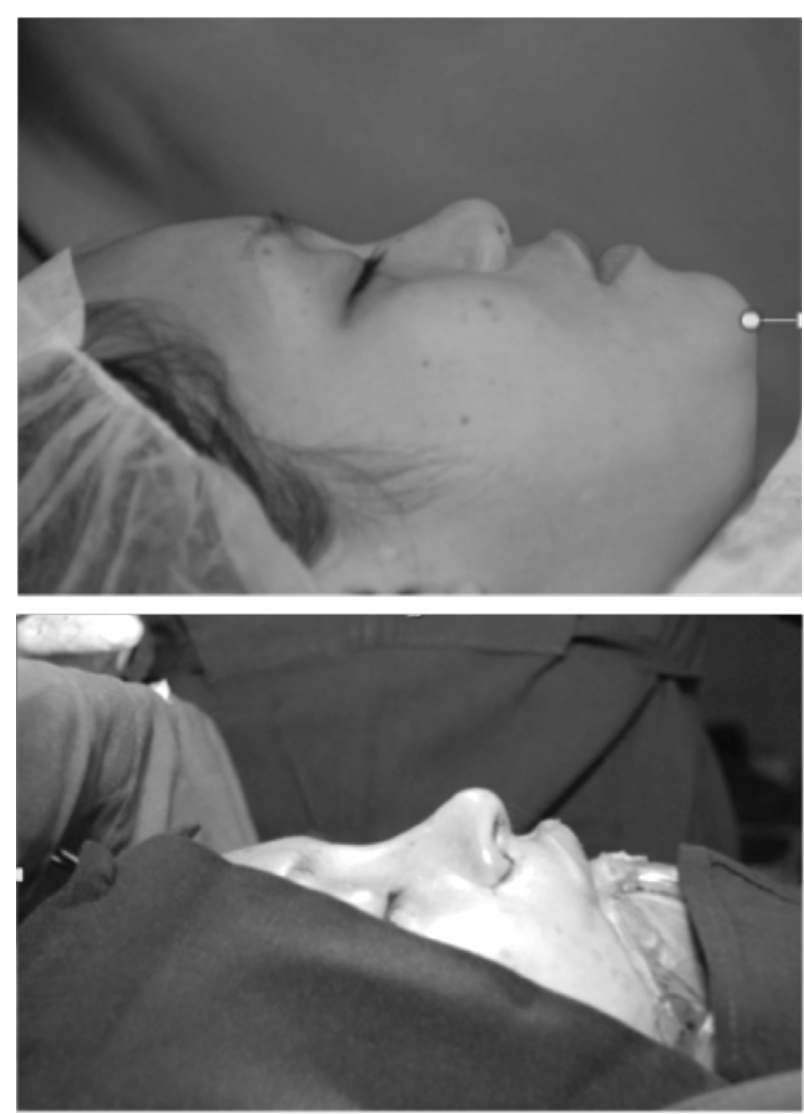

Figure 9. Pre op and immediate post op in the operating room
The new nose has to be taped with 3M"' Steri-Strip'" (St. Paul MN, USA) adhesive skin closures and covered with a thermal splint in order to control edema and fix the dorsal implant. Sutures and splint are removed after 5-7 days. (Figure 10)
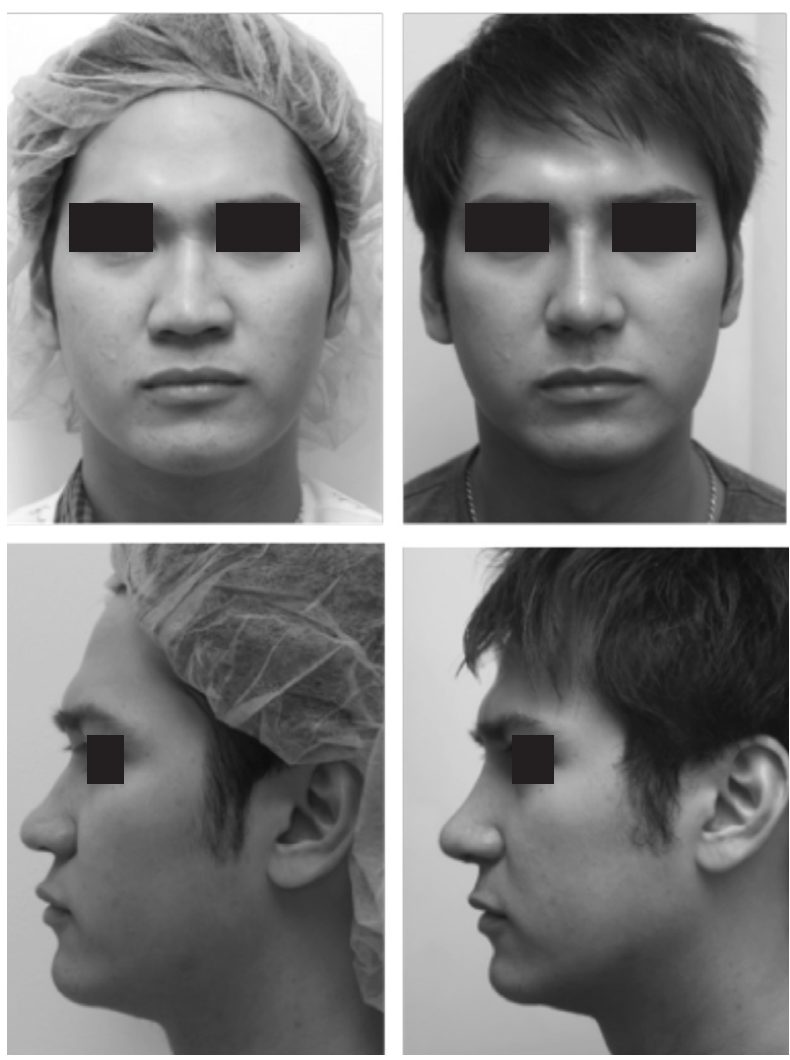

Figure 10. A typical SE Asian nose before and after open structural rhinoplasty. Note the improved nasal bridge, narrower ala, good columellar show, better ala-columella relationship, better tip projection and fuller premaxilla

\section{REFERENCES}

1. Berhbohm H, Tardy ME. Essentials of Septorhinoplasty. Stuttgart, Germany; Thieme. 2004. p. 49

2. Toriumi DM. Structure concept in nasal tip surgery. Operative Techniques in Plastic and Reconstructive Surgery. 2000 Jan; 7 (4): 175-186. DOI: 10.1053/otpr.2000.26065

3. Jang YJ. Rhinoplasty and Septoplasty. $1^{\text {st }}$ ed. Koonja Publishing. 2014. 371-392.

4. Choi JY, Kang IG, Javidinia H, Sykes JM. Complications of septal extension grafts in Asian patients. JAMA Facial Plast Surg. 2014 May-Jun; 16 (3); 169-175.

5. Yap EC, Abubakar SS, Olveda MB. Expanded polytetrafluoroethylene as dorsal augmentation material in rhinoplasty on Southeast Asian noses: three year experience. Arch Facial Plast Surg. 2011 Jul-Aug; 13(4): 234-238.

6. Baladiang DE, Olveda MB, Yap EC. The "sail" excision technique: a modified alar lift procedure for Southeast Asian noses. Philipp J Otolaryngol Head Neck Surg. 2010 Jan-Jun; 25(1):31-37

7. Yap EC. Improving the hanging ala. Facial Plast Surg. 2012 Apr; 28(2): 213-217. 